\title{
Stroke in South Asia: A Systematic Review of Epidemiologic Literature from 1980 to 2010
}

\author{
Ambar Kulshreshtha ${ }^{a, b}$ Laurie M. Anderson ${ }^{d}$ Abhinav Goyal ${ }^{a, b}$ \\ Nora L. Keenan ${ }^{c}$ \\ Departments of a Epidemiology and ${ }^{\mathrm{b}}$ Medicine, Emory University, and ${ }^{\mathrm{C}}$ Division for Heart Disease and \\ Stroke Prevention, CDC, Atlanta, Ga., and ' Washington State Institute for Public Policy, Olympia, Wash., USA
}

\section{Key Words}

Stroke $\cdot$ Stroke incidence $\cdot$ Stroke prevalence $\cdot$ Risk factors • South Asia

\begin{abstract}
Background: Globally 15 million people have an acute stroke every year and one third of them die secondary to stroke events. Most research on stroke prevention and treatment is done in developed countries, yet more than $85 \%$ of strokes occur in developing countries. In particular, stroke remains an underrecognized cause of death and disability in South Asia. Methods: We conducted a systematic review to identify reliable and comparable epidemiological evidence on stroke in South Asia from 1980 to 2010. Publications were screened for eligibility to identify only population-based stroke studies. Results: Of the 71 studies retrieved, only 6 studies from South Asia gave us acceptable estimates of the burden of stroke. Population-based studies from South Asia have stroke prevalence in the range of 45-471 per 100,000. The age-adjusted incidence rate varied from approximately 145 per 100,000 to 262 per 100,000. Rural parts of South Asia have a lower stroke prevalence compared with urban areas. Conclusions: Our review highlights the paucity of research data in South Asia. This must be addressed in order to accurately determine the burden of stroke in South Asia, so that specific policy recommendations can be formulated to combat the stroke epidemic in this region.
\end{abstract}

Copyright $\odot 2012$ S. Karger AG, Basel

\section{KARGER}

Fax +4161306 1234 E-Mail karger@karger.ch www.karger.com (c) 2012 S. Karger AG, Basel

$0251-5350 / 12 / 0383-0123 \$ 38.00 / 0$

Accessible online at:

www.karger.com/ned

\section{Introduction}

Stroke is a leading cause of death and disability globally [1]. Each year, 5.7 million people die from stroke and it is the second most common cause of death worldwide (9.7\% of all deaths), exceeded only by heart disease [2]. Stroke often leaves its survivors with severe disabilities that cause emotional and economic hardships for both patients and their families. It also poses enormous costs to healthcare systems [3]. Over $85 \%$ of strokes are reported from developing countries, however the proportion of funds directed towards prevention in these countries remains insufficient [4-7]. A recent systematic review of trends in global stroke incidence has reported a divergence between developed countries (42\% reduction) and developing countries (100\% increase) over the past 4 decades [8]. These variations could be attributed to widespread urbanization and consequent changing risk factor profiles, and lack of adequate prevention and treatment of stroke in developing countries.

Epidemiological studies in developing countries provide some evidence that stroke mortality rates tend to be as high as coronary heart disease rates [9]. However, reliable statistics from many of these regions are not available. South Asia has over one fifth of the world's population and is one of the most densely populated regions of the world. Health systems in this region have historically faced challenges such as infectious diseases, malnutri-

Ambar Kulshreshtha, MD, MPH

1518 Clifton Road NE, 2040L CNR

Emory University, Atlanta, GA 30322 (USA)

Tel. +1 2145045208

E-Mail akulshr@emory.edu 
tion, and high infant mortality. With increasing life expectancy, urbanization, and evolving patterns of diet and exercise in the last few decades, these economies are now facing an additional threat from chronic conditions like heart disease, stroke, and cancer.

Several studies have suggested that South Asia has among the highest rates of cardiovascular diseases globally [10]. Also, South Asians who have migrated to other regions are reported to have higher coronary heart disease rates compared with the native population $[10,11]$. However, there is minimal literature about stroke rates from South Asia and many of the current estimates have relied on hospital-based studies. Based on evidence from developed countries, almost one third of stroke patients are not admitted to hospital, thus leading to biases in such studies [12-14]. Access to healthcare facilities is a bigger problem in developing countries, where even fewer people with stroke obtain hospital-based care. Accurate knowledge of stroke risk factors, incidence, and prevalence from community-based studies is important to develop public health interventions that reduce the stroke burden in such regions. The purpose of our systematic review is to identify reliable and comparable epidemiological evidence of stroke in community settings in South Asia and to summarize estimates of incidence, prevalence, and case fatality.

\section{Methods}

Stroke represents a constellation of neurologic signs and symptoms that are caused by cerebral infarction, cerebral hemorrhage, or subarachnoid hemorrhage. In this systematic review, we used the World Health Organization case definition of stroke: 'rapidly developing clinical signs of focal (or global) disturbance of cerebral function, with symptoms lasting $24 \mathrm{~h}$ or longer or leading to death, with no apparent cause other than of vascular origin' [15]. The stroke types included: ischemic stroke, hemorrhagic stroke, and subarachnoid hemorrhage, but not transient ischemic attack. Using broad search terms relevant to cerebrovascular disease, we searched Medline, EMBASE, Global Health Database, and WHO regional databases from 1980 through 2010 for population-based reports on stroke incidence, prevalence, case fatality, and mortality in South Asia. We also conducted searches combining stroke terms with the following country names: Afghanistan, Bangladesh, Bhutan, India, Maldives, Nepal, Pakistan, and Sri Lanka. Reference lists of relevant published articles were screened for any papers missed in our literature searches. Finally, we requested published or unpublished data using online discussion groups (ProCor, World Stroke Foundation, and World Heart Federation) and direct communication with colleagues working in South Asia. All articles and published abstracts in English and any other languages relevant to stroke in South Asia were included. Additional searches were conducted in regional journals that are not indexed in Medline or EMBASE.
Publications were screened for eligibility in two stages to identify stroke data that were population-based (those that reported fatal and nonfatal strokes in the community). In the first round, we screened all titles and abstracts for potential eligibility. Specifically, titles and abstracts were included if they were population-based studies conducted in any South Asian country and they examined incidence, prevalence, case fatality or stroke-specific mortality for the period 1980 to 2010. Results of this literature search were stored in a Reference Manager 12 bibliographic database (Thomson Reuters, New York). In the second round, all potentially eligible titles were retrieved in full text and reviewed according to predefined criteria. We extracted data on year of survey, duration of study, country, location, characteristics of participants, sampling methods, response rate, sample size, definition of stroke, measurement tools, representativeness, and strengths and limitations of each study. An adaptation of the STROBE guidelines (strengthening the reporting of observational studies in epidemiology) was used to characterize potential risk of bias in these studies [16]. Standard protocol and data collection forms were used and uncertainties were resolved by discussion with authors. Information from included studies was abstracted and coded in a Microsoft Access data form by a trained study reviewer using a standard protocol. The database was screened periodically for duplicate citations. Finally, two authors independently assessed a random $20 \%$ of the abstracted papers for consistency. A formal meta-analysis was not undertaken because of the high degree of heterogeneity in the study methods and participants of the included studies.

\section{Results}

The flow chart in figure 1 summarizes the literature search and selection process. In the first stage of screening, we retrieved 71 potential studies. After excluding nonrelevant studies, 32 articles were reviewed fully for detailed abstraction. In the past 3 decades, only 6 studies from this region met eligibility criteria for providing information about the burden of stroke in the South Asia region [17-22]. All of these studies were from India (tables 1,2$)$. There were only 3 longitudinal studies that reported on incidence measures.

\section{Incidence and Prevalence}

Studies with a rigorous case ascertainment provide the most robust information about stroke incidence. These studies, however, are rare in developing countries as they require considerable resources. From the few longitudinal studies in South Asia, the reported crude stroke incidence is in the range of $123-145$ per 100,000 [20-22]. The age-adjusted incidence rate varied from 145 per 100,000 to 262 per 100,000 [20, 21] (table 2). Prevalence has been more commonly reported from the community-based surveys and it is estimated to be in the range of 45-471 
Fig. 1. Screening and selection of articles.

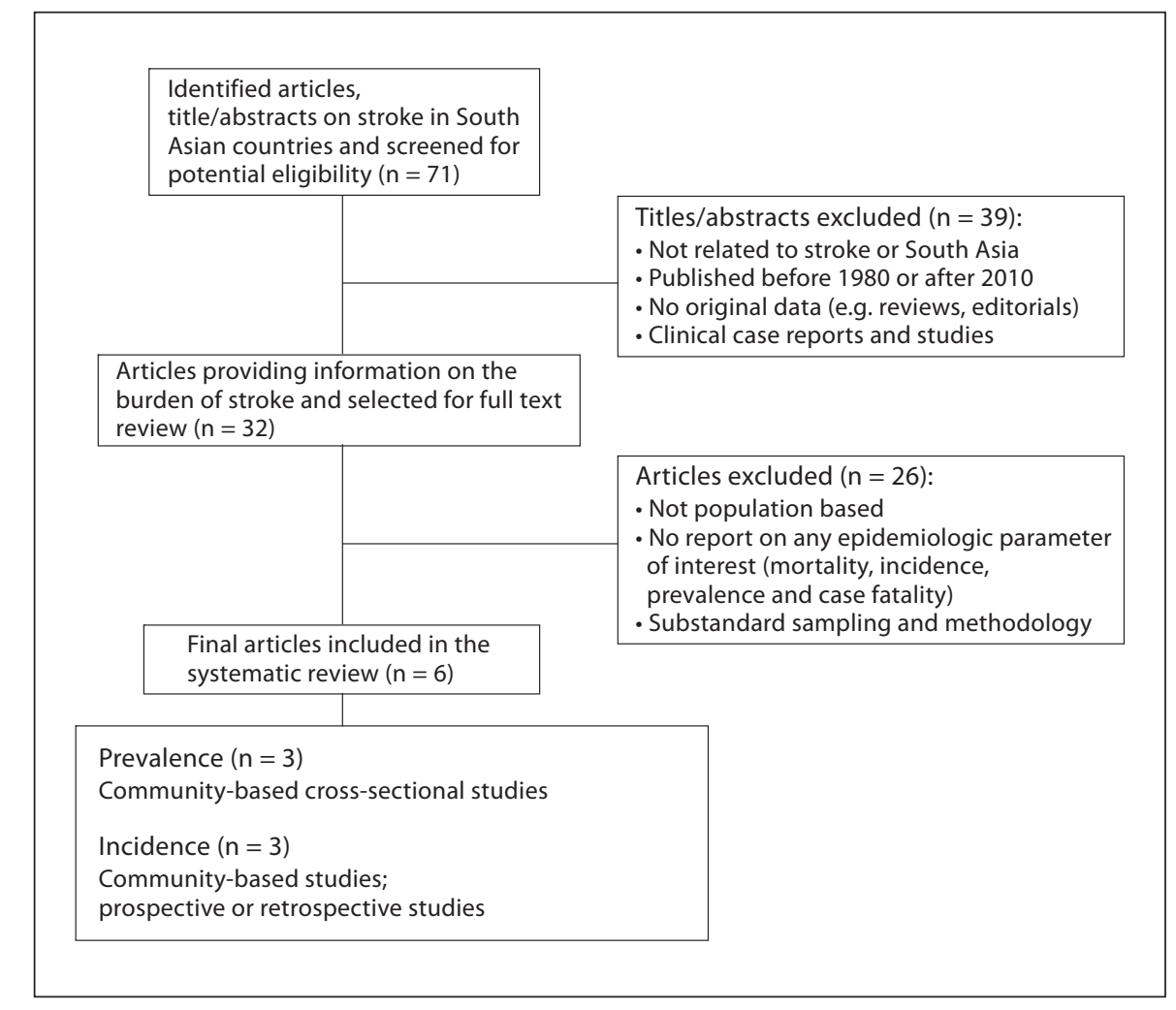

Table 1. Prevalence estimates from population-based studies on stroke in South Asia

\begin{tabular}{|c|c|c|c|c|c|c|}
\hline \multirow[t]{2}{*}{ Study } & \multirow[t]{2}{*}{ Location } & \multirow[t]{2}{*}{ Setting } & \multirow[t]{2}{*}{ Study design } & \multirow[t]{2}{*}{$\begin{array}{l}\text { Sample } \\
\text { size }\end{array}$} & \multicolumn{2}{|c|}{$\begin{array}{l}\text { Prevalence } \\
\text { (per 100,000) }\end{array}$} \\
\hline & & & & & crude & age-adjusted \\
\hline Razdan et al. [17], 1989 & India (Kashmir) & rural & population-based survey & 63,645 & 143 & $244^{\mathrm{a}}$ \\
\hline Dhamija and Dhamija [18], 1998 & India (Haryana) & rural & population-based survey & 51,165 & 45 & 47 \\
\hline Banerjee et al. [19], 2001 & India (Kolkata) & urban & population-based cluster survey & 50,291 & 147 & $334^{\mathrm{b}}$ \\
\hline Das et al. [21], 2007 & India (Kolkata) & urban & community-based longitudinal study & 52,377 & 471 & $545^{\mathrm{c}}$ \\
\hline
\end{tabular}

a Reference is USA population, 1960. ${ }^{\mathrm{b}}$ Reference is USA population, 1996. ${ }^{\mathrm{c}}$ Reference is world population, 2000.

Table 2. Incidence estimates from population-based studies on stroke in South Asia

\begin{tabular}{|c|c|c|c|c|c|c|}
\hline \multirow[t]{2}{*}{ Study } & \multirow[t]{2}{*}{ Location } & \multirow[t]{2}{*}{ Setting } & \multirow[t]{2}{*}{ Study design } & \multirow{2}{*}{$\begin{array}{l}\text { Sample } \\
\text { size }\end{array}$} & \multicolumn{2}{|c|}{ Incidence (per 100,000) } \\
\hline & & & & & crude & age-adjusted \\
\hline Bhattacharya et al. [20], 2005 & India (Bengal) & rural & community-based longitudinal study & 20,842 & 123 & $262^{\mathrm{a}}$ \\
\hline Das et al. [21], 2007 & India (Kolkata) & urban & community-based longitudinal study & 52,377 & 123 & $145^{\mathrm{b}}$ \\
\hline Dalal et al. [22], 2008 & India (Mumbai) & urban & population-based study & 156,861 & 145 & $152^{\mathrm{b}}$ \\
\hline
\end{tabular}

${ }^{a}$ Reference is USA population, 1990. ${ }^{\mathrm{b}}$ Reference is world population, 2000. 
per $100,000[18,21]$. Age-adjusted prevalence, however, is reported to be much higher and varies from 47 per 100,000 to 545 per $100,000[18,21]$. As in other developing countries, house-to-house surveys were often done as they are simple, efficient, and can be implemented in different settings.

\section{Stroke Mortality/Case Fatality}

Data on mortality can be obtained, but the accuracy of death certificate information on cause of death is often questionable [23]. Furthermore, they provide information only about fatal cases of stroke and not the proportion of stroke survivors who may be living with major disability. Very few studies in South Asia provided any information about stroke mortality. A population-based longitudinal study on stroke was undertaken in the city of Kolkata, India, to determine the subtypes, prevalence, incidence, and case fatality rates of stroke. Thirty-day case fatality rate was reported to be $41 \%(95 \% \mathrm{CI}=31-54)$ and it was slightly greater for women $(43 \%$; $95 \% \mathrm{CI}=30$ 61) than men (38\%; 95\% CI $=24-59)$. Most deaths $(86 \%)$ occurred among those aged 50 years and older [21].

\section{Urban-Rural Prevalence}

According to the World Bank, $70 \%$ of the South Asian population lives in rural areas and primarily relies on agriculture for their livelihood. Differences in rural-urban prevalence are of significant interest to better understand and control for stroke and its risk factors in these countries. Urban parts of South Asia have been shown to have higher prevalence of coronary artery disease and stroke [24]. In our screening, we found 3 studies that were done exclusively in rural areas. Our review shows that community surveys in rural parts of South Asia have a lower stroke prevalence in the range of $45-143$ per 100,000 compared with the reported prevalence of 147-471 per 100,000 in urban areas [17-19, 21].

\section{Age and Sex}

Risk factors and underlying causes of stroke differ significantly in young individuals compared to adults. Stroke events in the economically productive younger age group may lead to an additional burden for developing countries. We found no population-based study in South Asia that specifically looked at stroke and its risk factors in young adults. A community-based study in the Pashtun population in Karachi in Pakistan reported that 30\% of all strokes occurred at the age of less than 45 years [25]. Another case-control study was conducted in a tertiary care referral center in southern India which provided in- formation of stroke in the young [26]. The above screened studies were, however, excluded from our final review because of lack of a clear description of methods, although they provide some insights into stroke in the young. Increasing evidence suggests that sex differences exist in the etiology, management and outcome of stroke $[27,28]$. A survey done in Kolkata revealed the age-specific prevalence rate of stroke to be higher in women than in men in all age groups except in the 50- to 69-year age range [19]. A study by Bhattacharya et al. [20] in 2005 reported the sex-specific incidence (after age adjustment) to be 274 in women and 253 in men per 100,000.

\section{Stroke Subtypes and Risk Factors}

Population studies in South Asia have generally not specified the stroke classification or type of infarction due to limited diagnostic facilities in this region. In the Mumbai Stroke Registry, 80\% had ischemic stroke, 15\% had intracerebral hemorrhage, 3\% had subarachnoid hemorrhage and $2 \%$ were unspecified [22]. A longitudinal study conducted in Kolkata, India provided information on stroke subtypes with ischemic stroke reported as the most common subtype, and the ratio of infarction to hemorrhage was 1.9 [21]. Studies from South Asia have reported a similar risk factor profile as in other countries, with hypertension being the most frequent risk factor present, followed by smoking and diabetes $[19,20]$.

\section{Discussion}

The lack of high-quality stroke epidemiology data in developing countries is widely acknowledged by researchers and the World Health Organization [29]. In our systematic review of South Asia, few community-based epidemiological studies have been conducted to give a reliable estimate of the stroke burden. Only 6 studies in the last 3 decades provide reliable estimates of stroke epidemiology. All of these studies were from India, which may not yield a fair representation of the other countries in this region. Several studies that were screened had methodological weaknesses such as unclear sampling methodology, incomplete case ascertainment for valid estimation of stroke incidence, invalidated survey instruments, different definitions of stroke, no mention of a reference population used for standardization, and limited information about stroke subtypes to allow meaningful comparisons.

Age-adjusted stroke incidence rates in high-income countries have decreased from 163 per 100,000 in 1970- 
1979 to 94 per 100,000 in $2000-2008$, while in low- to middle-income countries the stroke incidence rates more than doubled (52 per 100,000 to 117 per 100,000, respectively) [8]. Age-adjusted incident rates reported in South Asia are higher (145-262 per 100,000) compared with other developing countries [21]. Studies of migrant South Asian populations in developed countries have similarly reported a higher incidence of stroke [30]. In neighboring countries such as China, the stroke incidence has been estimated to be 115-219 per 100,000 with intracerebral hemorrhage responsible for a vast majority of strokes [31]. In South Asia, ischemic stroke is the predominant stroke subtype similar to other regions of the world $[22,29]$. Epidemiological studies of age-adjusted prevalence in other countries have reported a higher rate of stroke, i.e. 500800 per 100,000 [32-34]. However, studies in South Asia report a lower age-adjusted prevalence of about 47-545 per 100,000 [35]. These lower prevalence rates in this region could be caused by a higher case fatality rate compared with other regions [21]. There are limited valid data on stroke-related mortality in South Asia, as ascertainment of cause of death is inadequate [36]. In a Karachibased study, in-hospital stroke mortality was reported to be $11 \%$ [37]. Our review suggests that there are sex-specific differences, and women have higher rates of stroke incidence and prevalence in South Asia [19]. Previous studies have shown that the prevalence of metabolic syndrome (in particular obesity) in Asian Indian women is 1.5-2.0 times higher as compared with men [37-40]. It is possible that many conventional risk factors like hypertension and diabetes are less well-managed in women than men. Further, studies on prevalence of smoking are lacking in South Asia women. More data are needed to better characterize and understand the prevalence and increased risk of stroke and its risk factors in the South Asian population.

Studies in South Asia suggest that with increasing urbanization level there is a general increase in stroke prevalence, and this is similar to trends observed in few other developing countries [41-43]. Comparing regional and temporal changes in stroke incidence is important for the understanding of stroke and its risk factors. For South Asia, there was little information to comment on temporal trends in stroke incidence, as studies were undertaken at different time periods in different areas. The WHOMONICA study was designed to monitor trends in the incidence of myocardial infarction and stroke and prevalence of risk factors, but it excluded many developing countries [44]. Recently, the INTERSTROKE study, a case-control study from 22 developed and developing countries, identified 10 risk factors that accounted for $90 \%$ of the population-attributable risk of stroke [45]. Modification of these risk factors through healthy lifestyle changes could substantially reduce the incidence of stroke in many of these countries. However, continuous surveillance of stroke and its risk factors to ascertain temporal trends is expensive and deemed impractical in most developing countries. A proposed solution has been to conduct a population-based incidence study in the same population once every decade [46].

Between 1990 and 2020, stroke is expected to increase by $120 \%$ for women and $137 \%$ for men in developing countries as compared with an increase of $30-$ $60 \%$ in developed countries [7]. However, financial resources for stroke prevention and treatment programs remain inadequate to meet the growing stroke burden in developing countries in the coming decades. Largescale and better designed epidemiologic studies, standardized registries, population-based stroke prevention programs, and improved surveillance systems are urgently needed to prevent, detect and treat stroke and its risk factors. Through our systematic review, we made a rigorous attempt to identify published reports on stroke in South Asia and critically assess the quality of these studies with strict criteria. Stroke studies that were population-based and methodologically comparable were included in the analyses. We excluded hospital-based studies as they are not reflective of the stroke burden in the community. Our systematic review is dependent on the quality of contributing studies and has a few limitations. First, although the world population and United States population was commonly used as standard, some of the older papers do not mention the reference population used for age adjustment and thus the adjusted rates may not be uniformly comparable. Second, there is no information in these studies about recurrent stroke events. It is possible that inclusion of recurrent events might have inflated our incident stroke rate, since people who have already had a stroke would be expected to have higher rates of recurrent events. Finally, although we made efforts to obtain unpublished data, it is difficult to identify all potential sources of unpublished data and thus a publication bias is still possible. However, inclusion of unpublished data will expose our review to data of lesser quality as these studies have not been vetted through the peer review process. Rigorous epidemiological studies can provide reliable estimates, assess time trends for valid comparisons, and yield data that would assist in improved planning of healthcare within these countries. 


\section{Conclusion}

The burden of stroke is underappreciated in South Asia. Levels of prevention, detection and treatment are extremely low, and the burden of stroke is projected to grow tremendously in the foreseeable future. In our systematic review, only 6 studies from South Asia provided acceptable estimates of the burden of stroke. There is a need for high-quality epidemiological studies in South Asia to monitor stroke incidence and prevalence, and to allow meaningful comparisons globally. Public health education and prevention efforts can be enhanced with well-designed population-based studies in South Asia to mitigate the stroke epidemic.

\section{Acknowledgements}

The authors thank Dr. George Mensah and Dr. Valery Feign for their advice and suggestions on the manuscript.

\section{Disclosure Statement}

The findings and conclusions in this report are those of the authors and do not necessarily represent the official position of the Centers for Disease Control and Prevention. There were no financial disclosures from any author.

\section{References}

1 Mackay JMG: The Atlas of Heart Disease and Stroke. Geneva, World Health Organization, 2004.

2 Mathers CD, Ma Fat D, Boerma JT: The Global Burden of Disease: 2004 Update. Geneva, World Health Organization, 2008

-3 Lopez AD, Mathers CD, Ezzati M, Jamison DT, Murray CJ: Global and regional burden of disease and risk factors, 2001: systematic analysis of population health data. Lancet 2006:367:1747-1757.

4 Feigin VL: Stroke epidemiology in the developing world. Lancet 2005;365:2160-2161.

$\checkmark 5$ Bonita R, Mendis S, Truelsen T, Bogousslavsky J, Toole J, et al: The global stroke initiative. Lancet Neurol 2004;3:391-393.

6 Tunstall-Pedoe H: Preventing Chronic Diseases. A Vital Investment: WHO Global Report. Geneva, World Health Organization, 2005, pp 200. http://www.who.int/chp/ chronic_disease_report/en.

7 Johnston SC, Mendis S, Mathers CD: Global variation in stroke burden and mortality: estimates from monitoring, surveillance, and modelling. Lancet Neurol 2009;8:345-354.

-8 Feigin VL, Lawes CM, Bennett DA, BarkerCollo SL, Parag V: Worldwide stroke incidence and early case fatality reported in 56 population-based studies: a systematic review. Lancet Neurol 2009;8:355-369.

9 Ebrahim S, Smith GD: Exporting failure? Coronary heart disease and stroke in developing countries. Int J Epidemiol 2001;30: 201-205.

10 Gupta R, Joshi P, Mohan V, Reddy KS, Yusuf $S$ : Epidemiology and causation of coronary heart disease and stroke in India. Heart 2008;94:16-26.

11 McKeigue PM, Miller GJ, Marmot MG: Coronary heart disease in south Asians overseas: a review. J Clin Epidemiol 1989;42:597-609.
12 Sudlow CL, Warlow CP: Comparable studies of the incidence of stroke and its pathological types: results from an international collaboration. International Stroke Incidence Collaboration. Stroke 1997;28:491-499.

13 Giroud M, Lemesle M, Quantin C, Vourch $\mathrm{M}$, Becker F, et al: A hospital-based and a population-based stroke registry yield different results: the experience in Dijon, France. Neuroepidemiology 1997;16:15-21.

14 Lacy CR, Suh DC, Bueno M, Kostis JB: Delay in presentation and evaluation for acute stroke: Stroke Time Registry for Outcomes KnowledgeandEpidemiology (S.T.R.O.K.E.). Stroke 2001;32:63-69.

15 Hatano S: Experience from a multicentre stroke register: a preliminary report. Bull World Health Organ 1976;54:541-553.

16 von Elm E, Altman DG, Egger M, Pocock SJ, Gotzsche PC, et al: The Strengthening the Reporting of Observational Studies in Epidemiology (STROBE) statement: guidelines for reporting observational studies. Lancet 2007;370:1453-1457.

17 Razdan S, Koul RL, Motta A, Kaul S: Cerebrovascular disease in rural Kashmir, India. Stroke 1989;20:1691-1693.

$\checkmark 18$ Dhamija RK, Dhamija SB: Prevalence of stroke in rural community - an overview of Indian experience. J Assoc Physicians India 1998;46:351-354.

19 Banerjee TK, Mukherjee CS, Sarkhel A: Stroke in the urban population of Calcutta - an epidemiological study. Neuroepidemiology 2001;20:201-207.

20 Bhattacharya S, Saha SP, Basu A, Das SK: A 5 years prospective study of incidence, morbidity and mortality profile of stroke in a rural community of eastern India. J Indian Med Assoc 2005; 103:655-659.
21 Das SK, Banerjee TK, Biswas A, Roy T, Raut DK, et al: A prospective community-based study of stroke in Kolkata, India. Stroke 2007;38:906-910.

22 Dalal PM, Malik S, Bhattacharjee M, Trivedi ND, Vairale J, et al: Population-based stroke survey in Mumbai, India: incidence and 28day case fatality. Neuroepidemiology 2008; 31:254-261.

23 Corwin LE, Wolf PA, Kannel WB, McNamara PM: Accuracy of death certification of stroke: the Framingham Study. Stroke 1982; 13:818-821

24 Goyal A, Yusuf S: The burden of cardiovascular disease in the Indian subcontinent. Indian J Med Res 2006;124:235-244.

25 Jafar TH: Blood pressure, diabetes, and increased dietary salt associated with stroke results from a community-based study in Pakistan. J Hum Hypertens 2006;20:83-85.

26 Lipska K, Sylaja PN, Sarma PS, Thankappan KR, Kutty VR, et al: Risk factors for acute ischaemic stroke in young adults in South India. J Neurol Neurosurg Psychiatry 2007;78: 959-963.

$\longrightarrow 27$ Niewada M, Kobayashi A, Sandercock PA, Kaminski B, Czlonkowska A: Influence of gender on baseline features and clinical outcomes among 17,370 patients with confirmed ischaemic stroke in the international stroke trial. Neuroepidemiology 2005;24: 123-128.

28 Turtzo LC, McCullough LD: Sex differences in stroke. Cerebrovasc Dis 2008;26:462474.

29 Feigin VL, Lawes CM, Bennett DA, Anderson CS: Stroke epidemiology: a review of population-based studies of incidence, prevalence, and case-fatality in the late 20th century. Lancet Neurol 2003;2:43-53. 
30 Gunarathne A, Patel JV, Gammon B, Gill PS, Hughes EA, et al: Ischemic stroke in South Asians: a review of the epidemiology, pathophysiology, and ethnicity-related clinical features. Stroke 2009;40:e415-e423.

-31 Liu M, Wu B, Wang WZ, Lee LM, Zhang SH, et al: Stroke in China: epidemiology, prevention, and management strategies. Lancet Neurol 2007;6:456-464.

-32 Aho K, Reunanen A, Aromaa A, Knekt P, Maatela J: Prevalence of stroke in Finland. Stroke 1986;17:681-686.

-33 Ostfeld AM, Wilk E: Epidemiology of stroke, 1980-1990: a progress report. Epidemiol Rev 1990;12:253-256.

-34 Baum HM, Robins M: The National Survey of Stroke. Survival and prevalence. Stroke 1981;12:I59-I68.

-35 Anand K, Chowdhury D, Singh KB, Pandav CS, Kapoor SK: Estimation of mortality and morbidity due to strokes in India. Neuroepidemiology 2001;20:208-211.
36 Ministry of Home Affairs Government of India, Registrar General of India: Medical Certification of Causes of Death 2007. New Delhi, 2007.

-37 Gupta R, Deedwania PC, Gupta A, Rastogi S, Panwar RB, et al: Prevalence of metabolic syndrome in an Indian urban population. Int J Cardiol 2004;97:257-261.

38 Misra A, Khurana L: The metabolic syndrome in South Asians: epidemiology, determinants, and prevention. Metab Syndr Relat Disord 2009;7:497-514.

39 Das M, Pal S, Ghosh A: Prevalence of cardiovascular disease risk factors by habitat: a study on adult Asian Indians in West Bengal, India. Anthropol Anz 2011;68:253-264.

40 Singh RB, Beegom R, Mehta AS, Niaz MA, De AK, et al: Social class, coronary risk factors and undernutrition, a double burden of diseases, in women during transition, in five Indian cities. Int J Cardiol 1999;69:139-147.

41 Lin HC, Lin YJ, Liu TC, Chen CS, Chiu WT: Urbanization and stroke prevalence in Taiwan: analysis of a nationwide survey. J Urban Health 2007;84:604-614.
42 Xue GB, Yu BX, Wang XZ, Wang GQ, Wang ZY: Stroke in urban and rural areas of China. Chin Med J (Engl) 1991;104:697-704.

43 Saposnik G, Del Brutto OH: Stroke in South America: a systematic review of incidence, prevalence, and stroke subtypes. Stroke 2003;34:2103-2107.

44 The World Health Organization MONICA Project (monitoring trends and determinants in cardiovascular disease): A major international collaboration. WHO MONICA Project Principal Investigators. J Clin Epidemiol 1988;41:105-114.

45 O’Donnell MJ, Xavier D, Liu L, Zhang H, Chin SL, et al: Risk factors for ischaemic and intracerebral haemorrhagic stroke in 22 countries (the INTERSTROKE study): a case-control study. Lancet 2010;376:112123.

46 Feigin V, Hoorn SV: How to study stroke incidence. Lancet 2004;363:1920. 